\title{
Desempenho de codornas de corte oriundas de diferentes classes de idades da matriz e de peso dos ovos
}

[Performance of European quails from different classes of breeder age and egg weight categories]

\author{
A.B. Corrêa ${ }^{1}$, M.A. Silva ${ }^{2}$, G.S.S. Corrêa $a^{1}$, G.G. Santos $^{3}$, R.R. Wenceslau ${ }^{3}$, V.P.S. Felipe ${ }^{3}$ \\ ${ }^{1}$ Faculdade de Medicina Veterinária - UFMT - Cuiabá, MT \\ ${ }^{2}$ Escola de Veterinária - UFMG - Belo Horizonte, MG - Bolsista de produtividade - CNPq \\ ${ }^{3}$ Aluno de pós-graduação - Escola de Veterinária - UFMG - Belo Horizonte, MG
}

\begin{abstract}
RESUMO
Estudou-se o efeito interação idade da matriz versus peso do ovo sobre o desempenho produtivo de codornas de corte (Coturnix coturnix coturnix) no $21^{\circ}$ e $42^{\circ}$ dias de idade. Em cada classe de idade da matriz, iniciada a partir de 70, 205 e 280 dias, foram incubados 600 ovos, separados em três categorias de peso: categoria 1 - ovos com 11,0-12,9g; categoria 2 - ovos com 13,0-14,9g; e categoria 3 - ovos com 15,0-16,9g. Após a eclosão, em cada idade da matriz, foram utilizadas 225 codornas de um dia, de ambos os sexos, provenientes das três categorias de peso, sendo 75 codornas por categoria. $\mathrm{O}$ delineamento experimental foi inteiramente ao acaso, com os tratamentos consistindo de um fatorial $3 \times 3$, ou seja, três classes de idades da matriz x três categorias de peso do ovo, com cinco repetições de 15 codornas por unidade experimental. A dieta experimental foi única para todos os tratamentos com $28 \%$ de proteína bruta e $2900 \mathrm{kcal}$ de energia metabolizável. O desempenho das codornas foi avaliado por meio das variáveis ganho de peso $(\mathrm{g})$, peso corporal $(\mathrm{g})$, consumo da dieta (g/ave) e conversão alimentar ( $\mathrm{g}$ de dieta/g de peso) no $21^{\circ}$ e $42^{\circ}$ dias de idade. Não houve interação significativa entre idade da matriz e categoria de peso do ovo sobre as características de desempenho das codornas. Codornas oriundas de ovos mais pesados e de matrizes das classes 205 e 280 dias de idade apresentaram maiores desempenhos. No $42^{\circ}$ dia de idade das codornas, não houve diferença para categoria de peso do ovo. Ovos mais pesados originaram codornas mais pesadas ao nascimento.
\end{abstract}

Palavras-chave: codorna de corte, desempenho, idade da matriz, peso do ovo

\begin{abstract}
The effects of breeder ages versus egg weight interaction on performance traits of European quail (Coturnix coturnix coturnix) at 21 and 42 days of age were studied in a completely randomized experimental design with 9 treatments, 5 replicates and 15 quails per experimental unit. The treatments consisted of a 3x3 factorial combination, three breeder ages (beginning at 70, 205 and 280 days of age) and three egg weight categories (category 1 - from 11.0 to $12.9 \mathrm{~g}$; category 2 - from 13.0 to $14.9 \mathrm{~g}$ and category 3 - from 15.0 to $16.9 \mathrm{~g}$ ). The quails were fed a unique experimental diet containing $28 \%$ crude protein and $2900 \mathrm{kcal}$ of metabolizable energy. The following performance traits were recorded: body weight $(\mathrm{g})$, weight gain $(\mathrm{g})$, feed intake $(\mathrm{g})$ and feed intake: weight gain ratio $(\mathrm{g} / \mathrm{g})$ at 21 and 42 days of age. No significant interaction effects between breeder age and egg weight categories were observed for all performance traits. Quails from heavier egg weight categories and breeder ages beginning at 205 and 280 days of age showed higher performance. No effects of egg weight categories on performance traits at 42 days of age were observed. Heavier egg weight categories resulted in a heavier quail at hatch.
\end{abstract}

Keywords: Meat type quail, performance, breeder age, egg weight

Recebido em 9 de novembro de 2010

Aceito em 27 de dezembro de 2011

E-mail: andrecorrea@ufmt.com

Apoio: FAPEMIG 


\section{INTRODUÇÃO}

A qualidade do pinto ao nascimento é um dos fatores mais importantes na cadeia de produção, pois está diretamente relacionada ao desempenho produtivo ao abate (Decuypere et al., 2001). A variação no peso do pinto no momento da eclosão pode ser causada por fatores como linhagem, idade da matriz, peso e níveis de nutrientes dos ovos (Vieira e Moran Jr., 1999; Rocha et al., 2008a), qualidade da casca, perda de peso durante o período de incubação (Reis et al., 1997 e Bruzual et al., 2000) e tempo de remoção dos pintos da incubadora.

A idade da matriz relaciona-se ao peso do ovo, que, por sua vez, tem forte influência no peso do pinto à eclosão (Reis et al., 1997; Tona et al., 2001; Rocha et al., 2008b e Corrêa et al., 2011). Vieira (2000) relatou que a ovulação do folículo pré-ovulatório primário (F1) em matrizes pesadas, logo que atingem a maturidade sexual, ocorre a cada 24-25 horas. Porém, à medida que as aves envelhecem, o intervalo de ovulação aumenta para 26-27 horas, ou mais, o que resulta em sequências de postura mais curtas e com intervalos mais frequentes, reduzindo a produção e aumentando o peso dos ovos.

Matrizes jovens põem ovos menores, com casca com menor quantidade de poros, cutícula e membranas mais espessas, albúmen mais viscoso e menor fonte de nutrientes, o que contribui para a eclosão de pintos menores, isto porque há menor disponibilidade de nutrientes para o crescimento do embrião (Benton Jr. e Brake, 1996). Contudo, com o aumento da idade das aves, a casca, a cutícula e as membranas tornamse mais finas, com melhora na concentração de nutrientes na gema e nascimento de pintos maiores (McLoughlin e Gous, 2000).

Shanawany (1984) observou que, no $18^{\circ}$ dia de incubação, o peso dos embriões de matrizes mais velhas foi maior que o de matrizes mais novas, sugerindo que esse efeito ocorreu em razão da maior porosidade da casca e da menor deposição de nutrientes na gema e da utilização mais eficiente dos nutrientes pelos embriões originados de aves mais velhas.

O peso do pinto de frangos de corte varia de $61,5 \%$ a $76 \%$ do peso do ovo (Shanawany, 1987). Assim, o uso de matrizes jovens resulta também na produção de pintos menos desenvolvidos, maior mortalidade e pior desempenho produtivo (Vieira e Moran Jr., 1999). Estes ovos, quando incubados juntos, resultam em lotes não uniformes e que acarretam problemas de manejo e ao abate das aves.

Embora as pesquisas demonstrem que o peso do ovo influencia o peso inicial dos pintos de corte, existem poucas informações na literatura sobre codornas de corte. Assim, buscou-se com este trabalho avaliar a influência de diferentes classes de idades das matrizes e categorias de pesos de ovos sobre o desempenho e as características de carcaça de codornas de corte do grupo genético EV2.

\section{MATERIAL E MÉTODOS}

Foram utilizadas 840 matrizes de codornas de corte (Coturnix coturnix coturnix) linhagem EV2, nas classes de idades iniciadas a partir de 70,205 e 280 dias. Em cada classe de idade da matriz, foram incubados 600 ovos, classificados em três categorias de peso (Categoria 1: 11,012,9g; Categoria 2: 13,0-14,9g e Categoria 3: $15,0-16,9 \mathrm{~g})$.

Após pesagem e classificação, os ovos, identificados com etiqueta adesiva numerada, foram acomodados em bandejas e incubados em temperatura e umidade controladas em $37,5^{\circ} \mathrm{C}$ e $60 \%$, respectivamente. No $15^{\circ}$ dia, os ovos foram colocados individualmente em saquinhos de filó (para total controle do indivíduo e do ovo) e transferidos para as bandejas de nascedouros, onde ficaram até o nascimento $\left(18^{\circ} \mathrm{dia}\right)$, à temperatura e umidade controladas $\left(37,2^{\circ} \mathrm{C}\right.$ e $70 \%$ ). Após eclosão, para cada idade da matriz foram utilizadas 225 codornas de um dia, de ambos os sexos, provenientes das três categorias de peso dos ovos, sendo 75 codornas de cada categoria de ovos. Essas 225 codornas de um dia, oriundas de cada classe de idade de matriz, foram distribuídas em delineamento inteiramente ao acaso, e os tratamentos, então, consistiram de codornas oriundas da interação entre três classes de idades das matrizes (70, 205 e 280 dias de idade) e três categorias de peso de ovo (11,0$12,9 \mathrm{~g} ; 13,0-14,9 \mathrm{~g}$ e $15,0-16,9 \mathrm{~g}$ ), totalizando nove tratamentos com cinco repetições de 15 codornas. As codornas, ao nascer, foram alojadas em baterias metálicas equipadas com bebedouro tipo copo e comedouro tipo calha. O programa de luz adotado foi de 23 horas diárias. A dieta única, para todos os tratamentos, continha $28 \%$ 


\section{Corrêa et al.}

de proteína bruta e 2900kcal de EM e foi formulada com base nas composições dos ingredientes apresentadas por Rostagno et al. (2000). O desempenho foi avaliado pelo ganho de peso (g), peso corporal (g) no $21^{\circ}$ e $42^{\circ}$ dias de idade, consumo da dieta (g/ave) e conversão alimentar ( $\mathrm{g}$ de dieta/g de peso) do nascimento ao $21^{\circ}$ e do nascimento ao $42^{\circ}$ dia de idade. A viabilidade foi determinada registrando-se o número de aves mortas no período dividido pelo total de aves no início do experimento, em cada categoria de peso de ovo dentro de cada classe de idade da matriz, multiplicado por 100 . A relação peso da codorna de 1 dia/peso do ovo foi calculada dividindo-se a média de peso da codorna de um dia pela média de peso dos ovos, em cada categoria de peso de ovo e dentro de cada classe de idade da matriz, multiplicado por 100.

Os resultados foram submetidos à análise de variância, e as médias comparadas pelo teste Student Newman Keuls a 5\% de probabilidade. As análises dos dados foram realizadas por meio do programa SAEG (Sistema...2004).

\section{RESULTADOS E DISCUSSÃO}

Não houve efeito significativo da interação entre classe de idade da matriz e categoria de peso do ovo para peso corporal (PC), ganho de peso (GP), consumo da dieta (CD) e conversão alimentar (CA) de codornas de corte do nascimento ao $21^{\circ}$ dia de idade (Tab. 1, 2, 3 e 4, respectivamente).

Tabela 1. Médias do peso corporal de codornas do grupo genético EV2 provenientes de matrizes de corte de três classes de idades e três categorias de peso dos ovos, do nascimento ao $21^{\circ}$ dia de idade

\begin{tabular}{|c|c|c|c|c|}
\hline \multirow{3}{*}{$\begin{array}{l}\text { Categoria de peso do } \\
\text { ovo }(\mathrm{g})\end{array}$} & \multicolumn{3}{|c|}{ Peso corporal $(\mathrm{g})$} & \multirow{3}{*}{ Média } \\
\hline & \multicolumn{3}{|c|}{ Classe de idade da matriz (dias) } & \\
\hline & 70 & 205 & 280 & \\
\hline $11-12,9$ & 144,9 & 145,7 & 149,8 & $146,8 \mathrm{c}$ \\
\hline $13-14,9$ & 149,2 & 155,1 & 155,4 & $153,2 b$ \\
\hline $15-16,9$ & 161,3 & 161,4 & 163,8 & $162,2 \mathrm{a}$ \\
\hline Média & $151,8 \mathrm{~A}$ & $154,1 \mathrm{~A}$ & $156,4 \mathrm{~A}$ & \\
\hline
\end{tabular}

Médias seguidas de letras distintas maiúsculas na linha e minúsculas na coluna diferem entre si pelo teste SNK, a 5\% de probabilidade. $\mathrm{CV}=3,3 \%$.

Tabela 2. Médias do ganho de peso de codornas do grupo genético EV2 provenientes de matrizes de corte de três classes de idades e três categorias de peso dos ovos, do nascimento ao $21^{\circ}$ dia de idade

\begin{tabular}{ccccc}
\hline \multirow{2}{*}{$\begin{array}{c}\text { Categoria de peso do } \\
\text { ovo }(\mathrm{g})\end{array}$} & \multicolumn{3}{c}{ Ganho de peso $(\mathrm{g})$} & \multirow{2}{*}{ Média } \\
\cline { 2 - 4 } & 70 & 205 & 280 & \\
\hline $11-12,9$ & 136,5 & 137,3 & 141,7 & $138,5 \mathrm{c}$ \\
$13-14,9$ & 139,5 & 145,6 & 146,1 & $143,7 \mathrm{~b}$ \\
$15-16,9$ & 150,3 & 150,6 & 152,9 & $151,3 \mathrm{a}$ \\
\hline Média & $142,1 \mathrm{~B}$ & $144,5 \mathrm{AB}$ & $146,9 \mathrm{~A}$ &
\end{tabular}

Médias seguidas de letras distintas maiúsculas na linha e minúsculas na coluna diferem entre si pelo teste SNK, a 5\% de probabilidade. $\mathrm{CV}=3,5 \%$.

Tabela 3. Médias de consumo da dieta de codornas do grupo genético EV2 provenientes de matrizes de corte de três classes de idades e três categorias de peso dos ovos, do nascimento ao $21^{\circ}$ dia de idade

\begin{tabular}{ccccc}
\hline \multirow{2}{*}{$\begin{array}{c}\text { Categoria de peso do } \\
\text { ovo }(\mathrm{g})\end{array}$} & \multicolumn{3}{c}{ Consumo da dieta $(\mathrm{g})$} & \multirow{2}{*}{ Média } \\
\cline { 2 - 4 } & 70 & 205 & 280 \\
\hline $11-12,9$ & 278,2 & 267,6 & $277,5 \mathrm{c}$ \\
$13-14,9$ & 285,8 & 282,1 & $286,7 \mathrm{~b}$ \\
$15-16,9$ & 301,9 & 291,5 & 298,2 & $304,1 \mathrm{a}$ \\
\hline Média & $288,7 \mathrm{~B}$ & $280,4 \mathrm{C}$ & 318,9 & \\
\hline
\end{tabular}

Médias seguidas de letras distintas maiúsculas na linha e minúsculas na coluna diferem entre si pelo teste SNK, a 5\% de probabilidade. $\mathrm{CV}=3,3 \%$. 
Observa-se para PC, GP e CD efeito significativo da classe de idade da matriz e categoria de peso do ovo (Tab. 1, 2 e 3), de forma que, dentro da categoria de peso do ovo, o PC, GP e CD das codornas de corte no $21^{\circ}$ dia de idade aumentaram à medida que a categoria de peso dos ovos foi mais pesada, ou seja, codornas provenientes de ovo com 15-16,9g apresentaram maiores PC, GP e CD, seguidas das codornas provenientes das categorias de peso do ovo 13$14,9 \mathrm{~g}$ e 11-12,9g, respectivamente. Estes resultados corroboram os observados por Corrêa et al. (2011), que encontraram maiores PC, GP e $\mathrm{CD}$ ao $21^{\circ}$ dia de idade, em codornas de corte EV1 provenientes de ovos mais pesados.

Estes resultados podem também ser explicados pelo fato de que ovos maiores apresentam maiores pesos de gema e concentração de proteínas e fosfolipídios ao final do período de incubação, quando ocorre a transferência de nutrientes do saco vitelino para o embrião, e resultam em maiores pesos de pintos ao nascer, e melhor desenvolvimento das aves durante a produção (Noble et al., 1986; Ding e Lilburn, 1996).

Dentro das classes de idades da matriz, não foi observado efeito significativo $(\mathrm{P}>0,05)$ para peso corporal (Tab. 1) nas codornas no $21^{\circ}$ dia de idade. Já para ganho de peso (Tab. 2), foram observados melhores desempenhos $(\mathrm{P}<0,05)$ para as codornas oriundas de matrizes da classe de idade iniciadas a partir de 280 dias $(146,9 \mathrm{~g}) \mathrm{em}$ relação àquelas matrizes de 70 dias de idade $(142,1 \mathrm{~g})$. As codornas provenientes das matrizes de classe de idades com 205 dias apresentaram desempenhos intermediários $(144,5 \mathrm{~g})$, porém não diferiram $(\mathrm{P}>0,05)$ das demais classes de idades das matrizes. Pinchasov (1991) observou que pintos de frangos de corte oriundos de matrizes mais velhas tenderam a ser mais pesados que aqueles oriundos de matrizes mais novas no $18^{\circ}$ dia de idade. Corrêa et al. (2011) trabalharam com codornas de corte EV1 e observaram que codornas oriundas de matrizes mais velhas apresentaram maior $\mathrm{PC}$ e maior GP ao $21^{\circ}$ dia de idade.

Em relação ao consumo da dieta (Tab. 3), codornas oriundas das matrizes provenientes de classes de idade iniciadas aos 280 dias apresentaram maior consumo $(301,3 \mathrm{~g})$ que as codornas das demais classes $70(288,7 \mathrm{~g})$ e 205
$(280,4 \mathrm{~g})$ dias de idade, respectivamente $(\mathrm{P}<0,05)$. Resultados semelhantes foram constatados por Dalanesi et al. (2005) e Corrêa et al. (2011), que observaram maiores consumos de dieta em frangos de corte e codornas de corte na fase inicial de crescimento, respectivamente, quando oriundos de matrizes mais velhas.

Não foi observada diferença na conversão alimentar para codornas oriundas das diferentes categorias de peso de ovo no $21^{\circ}$ dia de idade. Entretanto, houve efeito significativo da classe de idade da matriz sobre esta variável (Tab. 4), com melhor resultado $(1,94)$ observado nas codornas oriundas de matrizes da classe de idade iniciada a partir de 205 dias de idade. Matrizes da classe de idade com $70(2,03)$ e $280(2,05)$ dias não diferiram entre si $(\mathrm{P}>0,05)$. Corrêa et al. (2011) também encontraram melhores conversões alimentares nas codornas de corte EV1 provenientes das matrizes de classe de idade com 205 dias. A melhor conversão alimentar na classe de idade da matriz com 205 dias pode ser explicada pelo fato de ter sido observado menor consumo da dieta do nascimento ao $21^{\circ}$ dia de idade, o que refletiu em melhor CA.

Outra hipótese que explica a melhor CA das codornas oriundas da classe de idade da matriz de 205 dias pode ser em decorrência de alguma diferença que poderia existir no peso do saco vitelino das codornas dessa classe, o que refletiu no menor consumo de dieta (Tab.3) em razão do maior fornecimento de nutrientes pós-eclosão, via saco vitelino, conforme relatado por Romanoff (1960), o qual cita que as aves nascem com reserva nutricional presente no saco vitelino, que é de peso bastante variável, mas representa, em média, $10 \%$ do peso vivo dos pintinhos de frangos de corte.

$\mathrm{Na}$ avaliação do desempenho de codornas de corte do nascimento ao $42^{\circ}$ dia de idade, observou-se que não houve efeito significativo da interação classes de idades da matriz $x$ categorias de peso do ovo sobre peso corporal (PC), ganho de peso (GP), consumo da dieta (CD) e conversão alimentar (CA) e viabilidade (Tab. 5, 6, 7, 8 e 9, respectivamente). Entretanto, houve efeito da classe de idade da matriz e categoria de peso do ovo sobre as variáveis PC, GP e CD (Tab. 5, 6 e 7). 


\section{Corrêa et al.}

Tabela 4. Médias de conversão alimentar de codornas do grupo genético EV2 provenientes de matrizes de corte de três classes de idades e três categorias de peso dos ovos, do nascimento ao $21^{\circ}$ dia de idade

\begin{tabular}{ccccc}
\hline \multirow{2}{*}{$\begin{array}{c}\text { Categoria de peso do } \\
\text { ovo }(\mathrm{g})\end{array}$} & \multicolumn{3}{c}{ Conversão alimentar $(\mathrm{g} / \mathrm{g})$} & \multirow{2}{*}{ Média } \\
\cline { 2 - 4 } & 70 & Classe de idade da matriz (dias) & \\
\cline { 2 - 4 } & 2,04 & 205 & 280 & $2,00 \mathrm{a}$ \\
$11-12,9$ & 2,05 & 1,95 & 2,02 & $2,01 \mathrm{a}$ \\
$13-14,9$ & 2,01 & 1,94 & 2,04 & $2,01 \mathrm{a}$ \\
$15-16,9$ & $2,03 \mathrm{~B}$ & $1,94 \mathrm{~A}$ & 2,08 & \\
\hline Média & & $2,05 \mathrm{~B}$ & \\
\hline
\end{tabular}

Médias seguidas de letras distintas maiúsculas na linha e minúsculas na coluna diferem entre si pelo teste SNK, a 5\% de probabilidade. $\mathrm{CV}=3,0 \%$.

Tabela 5. Médias do peso corporal de codornas do grupo genético EV2 provenientes de matrizes de corte de três classes de idades e três categorias de peso dos ovos, do nascimento ao $42^{\circ}$ dia de idade

\begin{tabular}{ccccc}
\hline \multirow{2}{*}{$\begin{array}{c}\text { Categoria de peso do } \\
\text { ovo }(\mathrm{g})\end{array}$} & \multicolumn{3}{c}{ Peso corporal $(\mathrm{g})$} & \multirow{2}{*}{ Média } \\
\cline { 2 - 4 } & 70 & 205 & 280 & \\
\cline { 2 - 4 } $11-12,9$ & 269,3 & 275,2 & 279,8 & $274,8 \mathrm{~b}$ \\
$13-14,9$ & 271,1 & 283,2 & 292,9 & $282,4 \mathrm{~b}$ \\
$15-16,9$ & 288,6 & 291,7 & 297,7 & $292,7 \mathrm{a}$ \\
\hline Média & $276,4 \mathrm{~B}$ & $283,4 \mathrm{AB}$ & $290,1 \mathrm{~A}$ & \\
\hline
\end{tabular}

Médias seguidas de letras distintas maiúsculas na linha e minúsculas na coluna diferem entre si pelo teste SNK, a 5\% de probabilidade. $\mathrm{CV}=4,5 \%$.

Tabela 6. Médias de ganho de peso de codornas do grupo genético EV2 provenientes de matrizes de corte de três classes de idades e três categorias de peso dos ovos, do nascimento ao $42^{\circ}$ dia de idade

\begin{tabular}{ccccc}
\hline \multirow{2}{*}{$\begin{array}{c}\text { Categoria de peso } \\
\text { do ovo }(\mathrm{g})\end{array}$} & \multicolumn{3}{c}{ Ganho de peso $(\mathrm{g})$} & \multirow{2}{*}{ Média } \\
\cline { 2 - 4 } & 70 & 205 & 280 \\
\hline $11-12,9$ & 260,9 & 266,9 & 271,7 & $266,5 \mathrm{~b}$ \\
$13-14,9$ & 261,5 & 273,7 & 283,6 & $272,9 \mathrm{ab}$ \\
$15-16,9$ & 277,6 & 281,0 & 286,8 & $281,8 \mathrm{a}$ \\
\hline Média & $266,7 \mathrm{~B}$ & $273,8 \mathrm{AB}$ & $280,7 \mathrm{~A}$ & \\
\hline
\end{tabular}

Médias seguidas de letras distintas maiúsculas na linha e minúsculas na coluna diferem entre si pelo teste SNK, a 5\% de probabilidade. $\mathrm{CV}=4,6 \%$.

Os PC (Tab. 5) das codornas avaliadas no $42^{\circ}$ dia de idade, dentro da categoria de peso de ovo, foram maiores para codornas oriundas de ovos da categoria de peso entre 15-16,9g $(292,7 \mathrm{~g})$. Codornas provenientes das categorias de peso de $11-12,9$ e $13-14,9 \mathrm{~g}$ apresentaram PC de 274,8 e $282,4 \mathrm{~g}$, respectivamente, e não diferiram entre si $(\mathrm{P}>0,05)$.

Observou-se (Tab. 6) maior GP nas codornas oriundas das categorias de peso do ovo de 15$16,9 \mathrm{~g}(281,8 \mathrm{~g})$ e menor GP para aquelas das categorias de peso de ovo de 11-12,9g (266,5g). As codornas provenientes das categorias de peso de ovo de 13-14,9g (272,9g) não diferiram das demais categorias de peso do ovo. Isso pode ser atribuído ao fato de que ovos mais pesados deram origem a codornas mais pesadas ao nascimento (Tab. 10), e, consequentemente, estas apresentaram maiores pesos corporais e maiores ganhos de peso após o nascimento. Lara et al. (2005) observaram, em frangos de corte, que pintos mais pesados ao nascimento apresentaram maior PC e CD no $43^{\circ}$ dia de idade. Corrêa et al. (2011) também observaram maior peso corporal para codornas de corte EV1 oriundas de ovos mais pesados. Já dentro das classes de idade das matrizes, para as variáveis PC e GP (Tab. 5 e 6), observou-se que codornas oriundas de ovos de matrizes das classes de idade iniciadas a partir de 280 dias apresentaram maior PC e GP $(290,1 \mathrm{~g}$ e $280,7 \mathrm{~g}$ ), respectivamente, do que as codornas provenientes das matrizes de 70 dias de idade com PC e GP médio de 276,4g e 266,7g, 
respectivamente. Codornas oriundas da classe de idade da matriz iniciada com 205 dias de idade apresentaram PC 283,4g e GP 273,8 e não diferiram $(\mathrm{P}>0,05)$ das demais classes de idades das matrizes. Resultados semelhantes foram observados por Corrêa et al. (2011), que também encontraram maiores pesos corporais e ganhos de peso no $42^{\circ}$ dia de idade em codornas de corte EV1 oriundas de matrizes mais velhas.Houve maior consumo da dieta (Tab.7) para codornas oriundas de ovos da categoria de peso $15-16,9 \mathrm{~g}$ $(941,6 \mathrm{~g})$. Codornas oriundas das categorias de peso dos ovos de 11-12,9g e 13-14,9g apresentaram CD de 891,5 e 913,8g, respectivamente, e não diferiram entre si $(\mathrm{P}>0,05)$. Este resultado de $\mathrm{CD}$ na categoria de peso do ovo atribuído às codornas oriundas de ovos das categorias de peso de 15-16,9g ocorreu em função de as codornas apresentarem maior PC ao nascimento e, portanto, necessitarem de maior quantidade de alimento para atenderem suas exigências nutricionais de mantença e crescimento.

No $42^{\circ}$ dia (Tab. 7), observou-se maior CD das codornas oriundas de ovos das classes de idade da matriz iniciadas a partir de 205 e 280 dias, as quais não diferiram entre si $(\mathrm{P}>0,05)$. Corrêa $e t$ al. (2011) também observaram maiores consumo de dieta em codornas provenientes de ovos mais pesados e de matrizes de classes de idades mais velhas.

Não houve diferença significativa na conversão alimentar (Tab. 8) entre as classes de idade das matrizes e categoria de peso do ovo, à semelhança dos resultados observados em codornas de corte por Corrêa et al. (2011) e por Lara et al. (2005), em frangos de corte.

Tabela 7. Médias de consumo das dietas de codornas do grupo genético EV2 provenientes de matrizes de corte de três classes de idades e três categorias de peso dos ovos, do nascimento ao $42^{\circ}$ dia de idade

\begin{tabular}{ccccc}
\hline \multirow{2}{*}{$\begin{array}{c}\text { Categoria de peso do } \\
\text { ovo }(\mathrm{g})\end{array}$} & \multicolumn{3}{c}{ Consumo da dieta $(\mathrm{g})$} & \multirow{2}{*}{ Média } \\
\cline { 2 - 4 } & 70 & 205 & 280 & \\
\cline { 2 - 4 } $11-12,9$ & 884,3 & 900,5 & 889,7 & $891,5 \mathrm{~b}$ \\
$13-14,9$ & 880,8 & 924,0 & 936,7 & $913,8 \mathrm{~b}$ \\
$15-16,9$ & 921,7 & 948,8 & 954,4 & $941,6 \mathrm{a}$ \\
\hline Média & $895,6 \mathrm{~B}$ & $924,5 \mathrm{~A}$ & $926,9 \mathrm{~A}$ & \\
\hline
\end{tabular}

Médias seguidas de letras distintas maiúsculas na linha e minúsculas na coluna diferem entre si pelo teste SNK, a 5\% de probabilidade. $\mathrm{CV}=3,6 \%$.

Tabela 8. Médias de conversão alimentar de codornas do grupo genético EV2 provenientes de matrizes de corte de três classes de idades e três categorias de peso dos ovos, do nascimento ao $42^{\circ}$ dia de idade

\begin{tabular}{ccccc}
\hline \multirow{2}{*}{$\begin{array}{c}\text { Categoria de peso do } \\
\text { ovo }(\mathrm{g})\end{array}$} & \multicolumn{3}{c}{ Conversão alimentar $(\mathrm{g} / \mathrm{g})$} & \multirow{2}{*}{ Média } \\
\cline { 2 - 4 } & 70 & 205 & 280 & \\
\hline $11-12,9$ & 3,39 & 3,37 & 3,28 & $3,35 \mathrm{a}$ \\
$13-14,9$ & 3,37 & 3,38 & 3,30 & $3,35 \mathrm{a}$ \\
$15-16,9$ & 3,32 & 3,38 & 3,33 & $3,34 \mathrm{a}$ \\
\hline Média & $3,36 \mathrm{~A}$ & $3,38 \mathrm{~A}$ & $3,30 \mathrm{~A}$ & \\
\hline
\end{tabular}

Médias seguidas de letras distintas maiúsculas na linha e minúsculas na coluna diferem entre si pelo teste SNK, a 5\% de probabilidade. $\mathrm{CV}=2,9 \%$.

Não houve diferença significativa na viabilidade no $42^{\circ}$ dia de idade (Tab. 9) de codornas provenientes de diferentes categorias de peso do ovo. Já as codornas oriundas da classe de idade da matriz com 280 dias apresentaram maior viabilidade $(\mathrm{P}<0,05)$ do que codornas provenientes das matrizes com 205 dias de idade.
Entretanto, codornas das classes de idades da matriz de 70 dias não diferiam das demais classes de idades das matrizes $(\mathrm{P}>0,05)$. Corrêa et al. (2011), em experimento realizado com codornas de corte EV1, observaram maior viabilidade em codornas provenientes de ovos mais pesados. 


\section{Corrêa et al.}

Tabela 9. Médias de viabilidade das codornas do grupo genético EV2 provenientes de matrizes de corte de três classes de idades e três categorias de peso dos ovos, do nascimento ao $42^{\circ}$ dia de idade

\begin{tabular}{ccccc} 
Categoria de peso do & \multicolumn{3}{c}{ Viabilidade (\%) } & \multirow{2}{*}{ Média } \\
\cline { 2 - 4 } ovo $(\mathrm{g})$ & 70 & Classe de idade da matriz (dias) & \\
\cline { 2 - 4 } & 89,3 & 90,7 & 280 & $91,1 \mathrm{a}$ \\
$11-12,9$ & 93,3 & 89,3 & 93,3 & $92,9 \mathrm{a}$ \\
$13-14,9$ & 89,3 & 81,3 & 96,0 & $88,0 \mathrm{a}$ \\
\hline $15-16,9$ & $90,7 \mathrm{AB}$ & $87,1 \mathrm{~B}$ & 93,3 & \\
\hline Média & & $94,2 \mathrm{~A}$ & \\
\hline
\end{tabular}

Médias seguidas de letras distintas maiúsculas na linha e minúsculas na coluna diferem entre si pelo teste SNK, a 5\% de probabilidade. $\mathrm{CV}=8,4 \%$.

Observou-se (Tab. 10) que codornas oriundas de matrizes mais novas (70 dias de idade) apresentaram maior peso ao nascimento $(\mathrm{P}<0,05)$, porém com efeitos diferenciados para cada categoria de peso de ovo nas idades das matrizes de 205 e 280 dias de idade. Estes resultados estão de acordo com os relatados por
Roque e Soares (1994) e Santos et al. (2009). Contudo, McLoughlin e Gous (2000) indicaram que, com o aumento da idade das aves, a casca, a cutícula e as membranas tornam-se mais finas, com melhora na concentração de nutrientes na gema e nascimento de pintos maiores.

Tabela 10. Médias de peso da codorna de um dia do grupo genético EV2 provenientes de matrizes de corte de três classes de idades e três categorias de peso dos ovos

\begin{tabular}{ccccc}
\hline \multirow{2}{*}{$\begin{array}{c}\text { Categoria de peso do } \\
\text { ovo }(\mathrm{g})\end{array}$} & \multicolumn{3}{c}{ Peso da codorna de um dia $(\mathrm{g})$} & \multirow{2}{*}{ Média } \\
\cline { 2 - 4 } & 70 & 205 & 280 & \\
\hline $11-12,9$ & $8,41 \mathrm{Ac}$ & $8,36 \mathrm{Ac}$ & $8,10 \mathrm{Bc}$ & 8,3 \\
$13-14,9$ & $9,66 \mathrm{Ab}$ & $9,53 \mathrm{Bb}$ & $9,29 \mathrm{Cb}$ & 9,5 \\
$15-16,9$ & $11,02 \mathrm{Aa}$ & $10,76 \mathrm{Ca}$ & $10,88 \mathrm{Ba}$ & 10,9 \\
\hline Média & 9,7 & 9,5 & 9,4 &
\end{tabular}

Médias seguidas de letras distintas maiúsculas na linha e minúsculas na coluna diferem entre si pelo teste SNK, a 5\% de probabilidade. $\mathrm{CV}=0,6 \%$.

$\mathrm{Na}$ Tab. 11, observou-se que as relações entre peso da codorna de 1 dia (PC1d)/peso do ovo (PO) dentro da idade da matriz, para cada categoria de peso do ovo, apresentaram comportamentos diferenciados, de forma que as médias das relações foram melhores para as classes de idades das matrizes mais novas. Entretanto, não houve diferença $(\mathrm{P}>0,05)$ nas relações para classe de idade da matriz de 205 e
280 dias, na categoria de peso de 15-16,9g. Já nas relações observadas para categoria de peso do ovo, dentro de cada classe de idade da matriz, à medida que os ovos foram mais pesados, observaram-se melhores relações em todas as idades, com exceção das categorias de 11-12,9 e $13-14,9 \mathrm{~g}$ na classe de idade da matriz de 280 dias, as quais não apresentaram diferenças $(\mathrm{P}>0,05)$ entre as relações.

Tabela 11. Médias da relação peso da codorna de um dia (PC1d):peso do ovo (PO) do grupo genético EV2 provenientes de matrizes de corte de três classes de idades e três categorias de peso dos ovos

\begin{tabular}{ccccc}
\hline \multirow{2}{*}{$\begin{array}{c}\text { Categoria de peso } \\
\text { do ovo }(\mathrm{g})\end{array}$} & \multicolumn{3}{c}{ Relação PC1d / peso do ovo (\%)* } & \multirow{2}{*}{ Média } \\
\cline { 2 - 4 } & 70 & 205 & 280 & \\
\hline $11-12,9$ & $68,29 \mathrm{Ac}$ & $67,26 \mathrm{Bc}$ & $65,88 \mathrm{Cb}$ & 67,15 \\
$13-14,9$ & $70,48 \mathrm{Ab}$ & $68,29 \mathrm{Bb}$ & $66,50 \mathrm{Cb}$ & 68,42 \\
$15-16,9$ & $71,24 \mathrm{Aa}$ & $69,28 \mathrm{Ba}$ & $69,34 \mathrm{Ba}$ & 69,95 \\
\hline Média & 70,00 & 68,28 & 67,24 & \\
\hline
\end{tabular}

Médias seguidas de letras distintas maiúsculas na linha e minúsculas na coluna diferem entre si pelo teste SNK, a 5\% de probabilidade. $\mathrm{CV}=0,8 \%$.

* Relação peso da codorna de um dia:peso do ovo $=(\mathrm{PC} 1 \mathrm{~d} / \mathrm{PO}) * 100$. 
Nos resultados observados para relação PC1d/PO, infere-se que os ovos provenientes de diferentes classes de idades das matrizes e de diferentes categorias de peso dos ovos devem ser incubados separadamente, em razão das mudanças que ocorrem nos ovos incubáveis em função da idade da matriz e da categoria de peso do ovo.

\section{CONCLUSÕES}

Maior peso do ovo resulta em maior peso corporal, ganho de peso e consumo da dieta de codornas de corte no $21^{\circ}$ e $42^{\circ}$ dias de idade. Codornas oriundas de matrizes de classes de idade iniciadas aos 205 e 280 dias apresentaram melhores desempenhos para peso corporal, ganho de peso e consumo da dieta.

\section{AGRADECIMENTOS}

À FAPEMIG, pelo financiamento parcial do projeto.

\section{REFERÊNCIAS}

BENTON Jr., C. E.; BRAKE, J. The effect of broiler breeder age and length of egg storage on egg albumen during early incubation. Poult. Sci., v.75, p.1069-1075, 1996.

BRUZUAL, J.J.; PEAK, S.D.; BRAKE, J. et al. Effects of relative humidity during the last five days of incubation and brooding temperature on performance of broiler chicks from young broiler breeders. Poult. Sci., v.79, p.1385-1391, 2000.

CORRÊA, A.B.; SILVA, M.A.; CORRÊA, G.S.S. et al. Efeito da interação idade da matriz $\mathrm{x}$ peso do ovo sobre o desempenho de codornas de corte. Arq. Bras. Med. Vet. Zootec., v.63, p.433440, 2011.

DALANEZI, J.A.; MENDES, A.A.; GARCIA, E.A. et al. Efeito da idade da matriz sobre o desempenho e rendimento de carcaça de frangos de corte. Arq. Bras. Med. Vet. Zootec., v.57, p.250-260, 2005.

DECUYPERE, E.; TONA, K.; BRUGGEMAN, F. et al. The day-old chick: a crucial hinge between breeders and broilers. World's Poult. Sci. J., v.57, p.127-138, 2001.
DING, S.T.; LILBURN, M.S. Characterization of changes in yolk sac and liver lipids during embryonic and early posthatch development of turkey poults. Poult. Sci., v.75, p.478-483, 1996.

LARA, L.J.C.; BAIÃO, N.C.; CANÇADO, S.V. et al. Influência do peso inicial sobre o desempenho e o rendimento de carcaça e cortes de frangos de corte. Arq. Bras. Med. Vet. Zootec., v.57, p.799-804, 2005.

McLOUGHLIN, L.; GOUS, R.M. "Efecto del tamaño del huevo en el crecimiento pre y post natal de pollitos de engorde. Avicult. Professional, v.18, p.24-29, 2000.

NOBLE, R.C.; LONSDALE, F.; CONNOR, K. et al. Changes in the lipid metabolism of the chick embryo with parental age. Poult. Sci., v.65, p.409-416, 1986.

PINCHASOV, Y. Relationship between the weight of hatching eggs and subsequent early performance of broiler chicks. Br. Poult. Sci., v.32, p.109-115, 1991.

REIS, L.H.; GAMA, L.T.; CHAVEIRO SOARES, M. Effects of short storage conditions and broiler breeder age on hatchability, hatching time, and chick weights. Poult. Sci., v.76, p.1459-1466, 1997.

ROCHA, J.S.R.; LARA, L.J.C.; BAIÃO, N.C. et al. Efeito da classificação dos ovos sobre a uniformidade, o desempenho e o rendimento de abate de frangos de corte. Arq. Bras. Med. Vet. Zootec., v.60, p.1181-1187, 2008a.

ROCHA, J.S.R.; LARA, L.J.C.; BAIÃO, N.C. et al. Efeito da classificação dos ovos sobre o rendimento de incubação e os pesos do pinto e do saco vitelino. Arq. Bras. Med. Vet. Zootec., v.60, p.979-986, 2008b.

ROMANOFF, A.L. The avian Embryo: Structural and Functional Development. New York: The Macmillan Company, 1960. 1305p.

ROQUE, L.; SOARES, M.C. Effects of eggshell quality and broiler breeder age on hatchability. Poult. Sci., v.73, p.1838-1845, 1994. 


\section{Corrêa et al.}

ROSTAGNO, H.S.; ALBINO, L.F.T.; DONZELE, J.L. et al. Tabelas Brasileiras para Aves e Suínos: composição de alimentos e exigências nutricionais de aves e suínos. Viçosa, MG: Universidade Federal de Viçosa, 2000. $141 \mathrm{p}$.

SANTOS, J.E.C.; GOMES, F.S.; BORGES, G.L.F.N. et al. Efeito da linhagem e da idade das matrizes na perda de peso dos ovos e no peso embrionário durante a incubação artificial. Biosci. J., v.25, p.163-169, 2009.

SISTEMA de análises estatísticas e genéticas SAEG, Versão 9.0. Viçosa, MG:UFV, 2004.

SHANAWANY, M.M. Inter-relationship between egg weight, parental age and embryonic development. Brit. Poul. Sci., v.25, p.449-455, 1984.
SHANAWANY, M.M. Hatching weight in relation to egg weight in domestic birds. World's Poul. Sci. J., v.43,p.107-115, 1987.

TONA, K.; BAMELIS, F.; COUCKE, W. et al. Relationship between broiler breeder's age and egg weight loss and embryonic mortality during incubation in large-scale conditions. J. Appl. Poul. Res., v.10, p.221-227, 2001.

VIEIRA, S.L. Nutrição neonatal de aves: aspectos práticos, respostas metabólicas e desenvolvimento do sistema imune. In: SIMPÓSIO SOBRE ADITIVOS ALTERNATIVOS NA NUTRIÇÃO ANIMAL, 1., 2000, Campinas. Anais... Campinas: Colégio Brasileiro de Nutrição Animal, 2000. p.51-64.

VIEIRA, S.L.; MORAN Jr., E.T. Effects of egg of origin and chick post-hatch nutrition on broiler live performance and meat yields. World's Poul. Sci. J., v.55, p.125-142, 1999. 